\title{
SUPPORTING ENGINEERING STUDENTS IN ANALYSING SOCIAL SUSTAINABILITY OF A PRODUCT: LESSONS LEARNED
}

\author{
P. Lagun Mesquita and M. Missimer $\bowtie$ \\ Blekinge Institute of Technology, Sweden \\ $\triangle$ mis@bth.se
}

\begin{abstract}
Though many engineering schools are integrating sustainability in the curriculum, most are still struggling, especially with social sustainability. The aim with this study was to test a process created to help students work systematically with these issues. Results show that students in the study did indeed benefit from structured process support as their general knowledge level of social sustainability issues as well as their understanding of how to integrate them in a product assessment was very low. Reflections from teaching staff on how to further develop such a process are also shared.
\end{abstract}

Keywords: social responsibility, design education, design learning, life cycle assessment (LCA), process analysis

\section{Introduction}

Our world is facing unparalleled challenges from multiple fronts due to society's unsustainable behavior (Steffen et al., 2011). Such challenges result in a wide and diverse range of ecological impacts on our biosphere such as climate change, loss of biodiversity, chemical pollution and soil degradation affecting the earth's biosphere (WWF, 2010). Equally, our social systems are being degraded with issues such as ongoing poverty, inequality, and decreasing level of trust.

\subsection{The role of higher education}

Higher education plays an important role in training students to become creators of our future sustainable world (Blewitt, 2010). There has however, been challenges in introducing sustainability into higher education. Given these challenge a term called Education for Sustainable Development (ESD) has been coined to focus on both the role and underlying pedagogy required to create learning environments to foster student understanding in this field. In order to tackle the challenge of integrating ESD into education curriculum, the UN declared a decade for ESD in the year 2005 during which UNESCO identified key characteristics of ESD (UNESCO, 2005).

Since the ending of the decade for ESD, the UN released its new Sustainable Development Goals (SDGs) which show the UN's commitment to continued focus on the area of sustainable development. The SDGs portray a global agenda which is applicable to both developing and developed countries and which was ratified by all member states of the UN in 2015. In order to reach the SDGs by 2030, all countries must commit to aligning their activities with the SDGs (Sustainable Development Solutions Network, 2017). However, these goals will not be achieved 
unless countries mobilize governments, academia, civil society, and business. This requires an educated workforce and strong academic knowledge transfer thus intensifying the need for ESD within higher education.

\subsection{The role of engineering education}

Within the realm of higher education, one key sector which will have a large impact on the design and construction of our future sustainable systems is that of Engineering. The current students going through Bachelor and Master level higher education will require an understanding of the sustainability challenge facing humanity and the possible ways to design solutions that not only do no harm but also take into account the complexity of the underlying social and environmental systems on which we rely. Jones and Michelfelder write about "Care-ful Engineers" with a focus on "not just technical problem-solving, but inherently involves internalizing social and ethical values as part of the problemframing processes that lead to good solutions" (Jones and Michelfelder, 2015, p.2).

Though many Engineering schools are trying to develop their sustainability related curriculum, most are still struggling. A report by Forum for the Future summarizes that the engineering profession is failing to embrace the positive role engineers could play in securing a sustainable future (2000). John Barry (2012) coined the phrase 'technically competent barbarians' to describe current designers and engineers who are developing technological solutions that currently move humanity faster towards an unsustainable trajectory. Fitzpatrick (2016) takes John Barry's sentiments and argues that many current engineering educators are producing 'technically competent barbarians'. He states that "Moving into the future and in the context of sustainability, embracing the socioeconomic dimension of engineering is becoming a very important aspect of the job of engineering educators" (ibid, p.10).

\subsection{Engineering education in Sweden}

Sweden has a high level of sustainability awareness when compared with other regions in the world and there is a push from both government and society for higher education to address the concept of sustainability within its Engineering education. Two key areas where sustainability and/or sustainable development has been linked to Engineering education is within the Swedish Higher Education Ordinance and the international initiative of the CDIO, which is adopted in many Swedish Universities.

The Swedish Higher Education Ordinance (SHEO) (SFS, 1993, s. 100) requires that engineering education meets a number of learning outcomes focused on sustainability. Annex 2 of the Ordinance prescribes that for the degree of Master of Science in Engineering, the student shall, among other things: "[...] demonstrate the ability to develop and design products, processes and systems while taking into account the circumstances and needs of individuals and the targets for economically, socially and ecologically sustainable development set by the community." The Bachelor of Science in Engineering present similar requirements. The Swedish government leaves to the individual universities the detailing of what that looks like and how deep the student understanding of sustainability needs to be. This transfer of responsibility on the one hand promotes a lot of freedom for universities to define their own perspectives and agenda regarding sustainability. On the other hand, it does not facilitate the building of a common vision of what sustainability is and what role engineers need to play in helping society transition towards sustainability.

The CDIO, which stands for Conceive-Design-Implement-Operate, is an international initiative that has put forward a framework and syllabus guiding the development of engineering education worldwide. This CDIO Syllabus, is "an attempt to create a rational, complete, consistent, and generalizable set of goals for undergraduate engineering education" (Crawley et al., 2011, np.). The CDIO syllabus was first produced in 2001 but has since been updated in 2011 with the update significantly increasing the awareness of sustainability and its related issues within engineering education in the hopes that higher education can mobilize student ready to meet the global challenges facing us as a population today. What the CDIO so far has failed to provide is a clear outline of what is contained within the context of "sustainable development" and in particular the requirements of engineers to have an understanding of the social aspects of sustainability. 
The higher education ordinance and the CDIO taken together as the key guiding documents for Swedish engineering educators clearly show that sustainable development and its related fields are of great importance within Engineering education and yet there is still a lack of clarity around the key definition of terms and no specific guidance on how universities should include content relating to sustainability within their respective curriculum.

\subsection{Social sustainability in Swedish engineering education}

Despite the efforts in integrating sustainability in national and international higher education frameworks, the implementation of such objectives appears to still be a challenge, in particular regarding social sustainability, as highlighted in a study from Australia (El-Zein et. al., 2008). A study conducted at KTH Royal Institute of Technology (Edvardsson Björnberg et al., 2015) showed that amongst the different pillars of sustainability, the social pillar is the one the least developed in connection to engineering education. Participants in the study also suggest that the lack of a conceptual framework that can clarify the contours of social sustainability in an engineering context creates uncertainty of how social sustainability can be best taught, learned and ultimately integrated in engineering practice. A further search on social sustainability in engineering education in Sweden delivered no valuable results.

At the Blekinge Institute of Technology (BTH) in Karlskrona, during this last two years there has been a conscious effort to increase the sustainability literacy amongst engineering students. One result from this work was the finding that teachers had a stronger understanding and theoretical knowledge of the environmental aspects of sustainability in comparison to that of social sustainability, confirming the same results from the study at KTH. So how can we advance the work with social sustainability in engineering education?

\subsection{Aim of paper}

This paper presents the findings from a study on how to best support engineering students to work with social sustainability, in this case to analyze the social sustainability impact of a product. Both authors of the paper have for many years worked with teaching social sustainability to engineering students at Blekinge Institute of Technology and have through this work created processes to support students in this work. The aim with the study reported here was to test a process created to help students work systematically with these issues. Would this process actually help students work with analyzing social sustainability impacts of a product? The following section describes the approach to social sustainability the exercise was built on and the method that was employed for the testing.

\section{Research approach + design}

\subsection{Social sustainability approach}

Recent research on social sustainability developed at BTH by Missimer et al. (2017a, 2017b) has opened up new possibilities in bringing clarity to the concept of social sustainability and also how to practically implement it. It is this approach that the process support was built on. The approach is based on the Framework for Strategic Sustainable Development (FSSD). In the FSSD, sustainability is about the not-undermining of the ecological and social system that humans rely on for their wellbeing. A social system is defined as human social agents (individuals and various constellations of groups) and the various relationships between these social agents. Further, the framework identifies five mechanisms by which social systems can be undermined and flips these into sustainability principles by framing them as the things that should not be done. In order to move towards sustainability, companies and other organizations should remove their contributions to people being subject to structural obstacles to ...

...health: This means that people are not exposed to social conditions that systematically undermine their possibilities to avoid injury and illness; physically, mentally or emotionally, e.g. dangerous working conditions or insufficient wages. 
...influence: This means that people are not systematically hindered from participating in shaping the social systems they are part of, e.g. by suppression of free speech or neglect of opinions.

...competence: This means that people are not systematically hindered from learning and developing competence individually and together, e.g. by obstacles for education or insufficient possibilities for personal development.

...impartiality: This means that people are not systematically exposed to partial treatment, e.g. by discrimination or unfair selection to job positions.

...meaning-making: This means that people are not systematically hindered from creating individual meaning and co-creating common meaning, e.g. by suppression of cultural expression or obstacles to co-creation of purposeful conditions.

The term structural obstacles refers to social constructions - political, economic and cultural - which are firmly established in society, upheld by those with power and, due to a variety of dependencies, difficult or impossible to overcome or avoid by the people exposed to them. The emphasis on structural obstacles is important. It is not the one-off-action violating the above that lead to social unsustainability. It is when such violations are embedded in the way a society organizes itself, that we have a serious problem. Structural obstacles can also be understood as the closest to root causes of social problems. Identification of such root causes is therefore vital if we are to design effective solutions to social problems.

\subsection{Test set-up}

The testing occurred with students in two different classes. The first class consists of 70 Swedish engineering students, 58 of which attended the workshop. These students come from three different 5-year engineering programs, that finish with a Master of Science in Marine Technology, Master of Science in Mechanical Engineering and Master of Science in Industrial Management and Engineering. The three programs all take the mandatory course Sustainability Basics in the 2nd year, that is to say in the Bachelor's portion of their program, but it is the first full sustainability course for all. The testing workshop was a part of this course. All students had previously attended a lecture that introduced the social sustainability approach described above and were expected to have read a book chapter on that same approach, but as in the previous testing, had not yet received any support in how to work with the approach, e.g. for a social sustainability analysis. However, the students had, in prior weeks, done a life-cycle analysis from an ecological perspective. For the purpose of the workshop two groups were created. In Group 140 students attended the workshop, in Group 2 18. For this class the processes were run in sequence rather than in parallel. This means that all students in smaller groups were first given the process with minimal instructions (first round) and then a reflection exercise followed by the structured process (second round) with a reflection exercise.

The second class consisted of 15 international master's students, mostly from India, but also Iran and China, who are at BTH to take the master's program in Structural Mechanics. They take the course Introduction to Strategic Sustainable Development, which this testing workshop was a part of, in their first year of study. All students had previously watched online video and attended a discussion and workshop, on the basics of the social sustainability approach described above, but had not yet received any support in how to work with the approach, e.g. for a sustainability analysis. In the workshop with this class there were two different sections, with two groups each, which ran exercises in parallel. One section received minimal instructions, one section received an elaborated and structured approach (from now on referred to as the structured approach), which will be described later on. The sections did not interact in the timeframe of the workshop and each section had an instructor to answer any questions and help along in the process. After the work, each group received a set of reflection questions. They then received the instructions from the other section and were asked whether they thought the change in instructions changed anything. This was followed by a whole class debrief and run-through of the processes, so that each group could leave the classroom with a similar knowledge level. 


\subsection{Process descriptions}

The two processes referred to above were as follows. The first process with minimal instructions simply stated the question "What structural obstacles to health/ influence, competence, impartiality and meaning-making can be found in connection to a steel knife?" The more elaborated process asked the students to take a life-cycle perspective and provided them with a template of seven life-cycle stages in the making of a steel knife from the raw material extraction (stage 1) and the consequent production of steel (2) to the transportation (3), the manufacturing of the knife (4), the packaging, marketing, and selling (5) the use phase (6) as well as the end of life phase (7). For each stage, students were asked to do the following:

1. Find out the location for each life-cycle stage. In the workshop we gave them iron ore as a key raw material to be analyzed and Brazil as the location of the iron ore mining to save time.

2. Make a list of issues that occur in this country using https://www.amnesty.org/en/countries/. The site was chosen because it gives a good, quick overview of social challenges in a country.

3. Map the issues to the social sustainability principles (as presented above)

4. Pick 3 issues and discuss the structural obstacles underlying the issue in that country. The guidance question given here was: What are the structures (official procedures/routines or rules/regulations/policies/laws or cultural norms/values/customs or organizational practices/ patterns) at national/regional or sectoral level that contribute to these issues?

5. Brainstorm actions that a company might take to help combat the existing "external" structural obstacles

6. What structural obstacles may exist within the organization regardless of its external context?

While an analysis of all life-cycle stages would, of course, be required for a full analysis, and knowing that other minerals and metals are also relevant for steel production, the students were only asked to complete the raw material extraction phase of iron ore in this workshop due to time constraints.

\subsection{Rationale for process}

A number of elements were identified in the literature and also from practice as necessary/important for the social sustainability analysis of a product. These are:

- To take a full life-cycle perspective, that includes identifying the activities that take place in these life-cycle stages

- To identify the location of the different life-cycle stages

- To consider different stakeholders (or affected groups of people)

Product systems, as defined in Dreyer et al. (2005), encompass "all the processes involved in the different stages of the product's life from the extraction of raw materials, through manufacture, use and maintenance, to the final disposal of the product" (ibid). For a product system, up until recently very few questions have been asked about its dependence and influence on the general regional and global social systems and subsystems like value chains and other stakeholder networks. One of the strengths of current Social-LCA approaches is that they clarify how a product system may connect to social systems and it is proposed that it is the quality of those connections, i.e the conduct of companies carrying out activities, that determines how positive or negative the impacts are on the social system (Benoit et al., 2010). Therefore, for the design of the more elaborated process the elements above were included in steps 1 and 2 in a way that it would become more evident for the students that location and local actors' behaviors and practices can determine the existence of negative or positive social impacts in connection to the different life-cycle activities of a product. In addition, the social sustainability approach on which the process was based was intended to help students in steps 3 and 4 to organize and make sense of social issues that often times due to its complex are not so obviously connected to a product's system. Step 5 was designed to tease students into moving to the problem-solving space and yet further their understanding of the interdependencies between local solutions and structural challenges. Finally the last step was designed to bring students back to a focal organization and consider whether there may be structural obstacles within the organization regardless of its external context, which could also 
create challenges for the long-term survival of that organization even if it is embedded in a context where social problems are not as pressing.

\section{Findings}

\subsection{Analysis results and reflections from Bachelor level class}

In the two workshops with this class there were a total of 15 groups. As a reminder, these groups did the two approaches in sequence, starting with minimal instructions (first round) and then re-doing the exercise with the provided structured process (second round). The results from the workshop are structured in the following categories of analysis:

- presence of a lifecycle perspective: since the students had, in prior weeks, done a life-cycle analysis from an ecological perspective, we were interested in knowing if the students would see similarities between the ecological and the social dimensions and activate previous knowledge by taking a lifecycle perspective also when doing a social sustainability analysis. As introduced previously, social impacts occur across different lifecycle stages and a comprehensive analysis requires taking these into account. In round two the students were given the task to look at different lifecycle stages, so this category only applies to round one.

- identification of social issues and of structural obstacles; in round one the students were guided only by the formulation of the social sustainability principles and asked to directly identify structural obstacles to social sustainability, whereas in round two the students where guided through a two-step approach. The approach required the students to first formulate and map social problems to then identify root causes (i.e. structural obstacles) and were given country specific data. We were interested in finding out their ability to do so;

- and a comparison of level of difficulty between rounds: by providing two levels of instructions we wanted to test the need for support beyond the provision of a definition of social sustainability and also evaluate the support created.

Results are presented in Figure 1 and elaborated below.

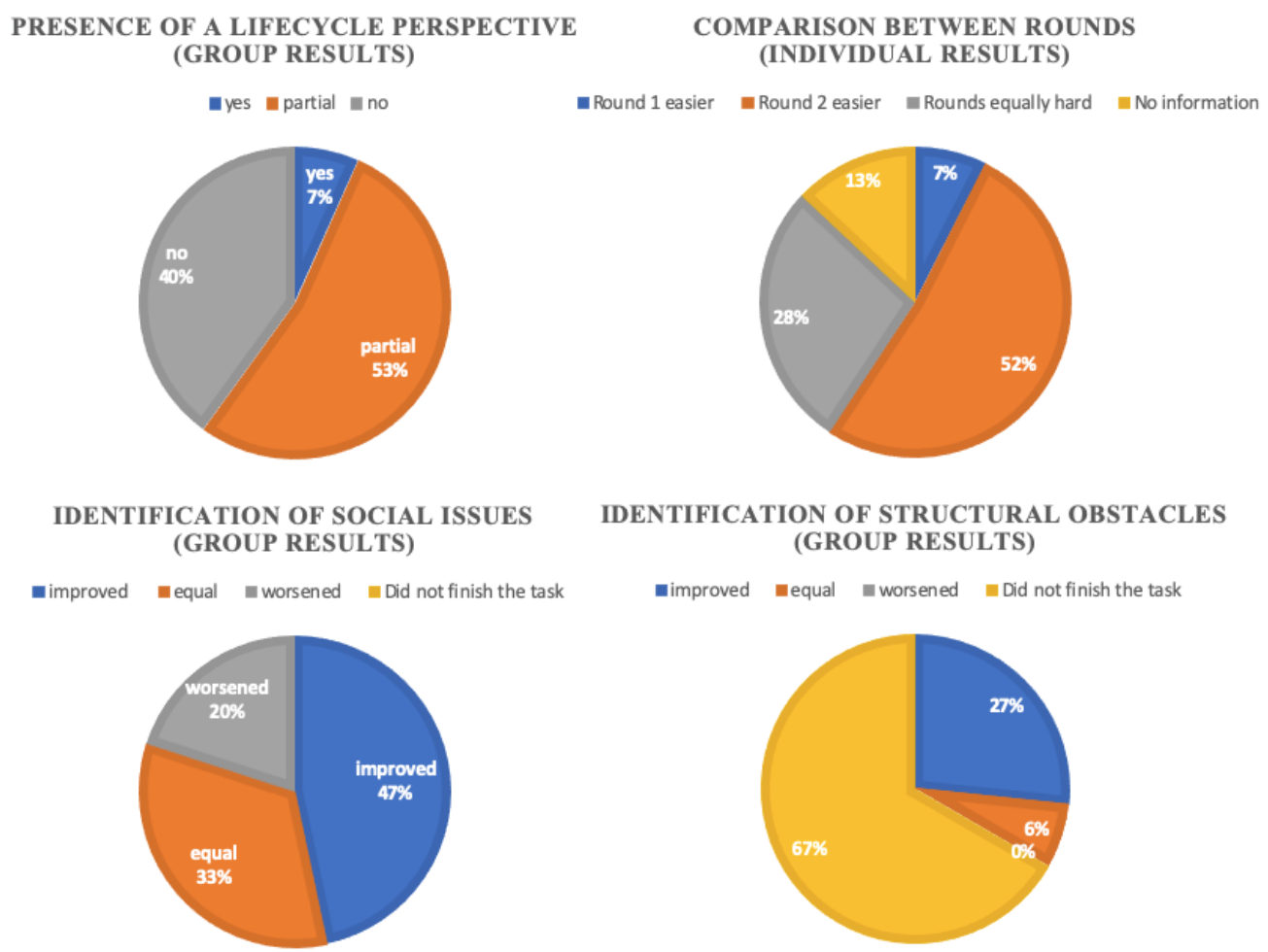

Figure 1. Cross group analysis 


\subsubsection{Presence of a lifecycle perspective}

More than half of the student groups (eight groups) took a partial lifecycle perspective when analyzing the social sustainability of a steel knife. Examples of social issues or structural obstacles were identified in one or more lifecycle stages, mostly related to manufacturing, but also some related to raw material extraction and product use. No examples related to end-of life where identified. Only one group identified at least one example of social in each SSP/life-cycle stage. Six groups did not take a lifecycle perspective and examples of issues/obstacles given by those groups indicate that the students were not very clear of what was being asked in the activity.

\subsubsection{Identification of social issues and structural obstacles}

Although students in the first round were prompted to identify structural obstacles as their main task, only five out of ten groups were able to give at least one example. Only one group produced examples of structural obstacles to all five principles. The remaining groups were able to formulate social issues related mostly to impacts on health from manufacturing processes and product use. In the evaluation by the students regarding the challenges in identifying structural obstacles, results were mixed. Some evaluated it as challenging; others as easy, even though the examples they gave were not correct. This indicates that the level of confidence does not align with the quality of the results.

In the second round, as the students received additional resources for the identification of issues, we saw an improved performance as expected. Seven groups were able to deliver a more comprehensive list of social issues and five others produced a similar level of quality. Surprisingly three groups performed worse in the second round; instead of formulating social problems based on the reading provided, they produced a list of headings borrowed from the text.

As for the identification of structural obstacles in the second round, four groups improved their ability to formulate structural obstacles and one group produced similar results as in the first round. Ten groups however did not manage to complete the task within the time given.

\subsubsection{Comparison of level of difficulty between rounds}

After each round, students were asked to reflect individually on their experience with the activity, rate the level of difficulty and compare the two exercises. Four out of 54 students evaluated the first round as easier and 28 students thought the second round was easier. 15 students thought that both rounds were equally hard. Seven students provided no answer to the question. Interestingly, when comparing the two rounds 20 students expressed that the second round was more extensive and demanding but also more supportive to performing the activity. Some students had expressed that for round one their low level of knowledge about the making of steel knives was a challenge and that that the second round was more easily done due to the structure of the process, including naming lifecycle stages and because a country and data were provided. However, for some the focus on country analysis obscured the connections between the product and social sustainability impacts.

The groups in this setup did not manage to complete the steps 5 and 6 and therefore cannot be analyzed. A general complaint from the students was the lack of time to be able to perform all the steps.

\subsection{Analysis results and reflections from international master's class}

In the workshop with this class there were a total of four groups, two performing the analysis with minimal instructions and two with the structured process. This means that groups had slightly more time to perform the analysis and therefore both groups that used the structured process managed to complete steps five and six. Although the groups we also asked to reflect on the differences of the approaches, the fact, that they did not get the opportunity to try both processes, means that their insights on comparing the approaches are of a theoretical nature rather than from a lived experience. Therefore, results from this group are presented in a narrative form.

The results from the groups with minimal instructions in the international Master's class show that the analyses students performed were very surface level. One group (Group 1) focused the analysis on the use phase only, meaning they looked at the implications of using the knife on health, influence, 
competence, etc. The other group (Group 2) came up with one issue per social sustainability principle, but the issues were sometimes unclear or incorrect, for example the structural obstacle to influence read "being threatened by the wrong people in society".

When asked to reflect on the experience and what would have changed if they had had the more structured set of instructions, the answers varied significantly within each group. Group 1 voiced that it was complex to identify structural obstacles and that is was hard to apply the principles to a steel knife or connect social sustainability in general, but that they thought "they got the hang of it". While some in the group thought that the structured approach would have indeed provided more structure, some thought it didn't change anything and some that it would have enabled them to get the answer quicker "because it structured the answers in the correct way". In group 2, some had found it very hard, some found it easy. They found the structural obstacles as they called it "directly" related to the steel knife easy (meaning to the use of the knife), but seemed aware that there were more indirect connections, which were harder. They reflected that the structured approach would have provided a more global as well as structured perspective.

The results from the groups with the structured approach in the international Master's class show more a thorough and thoughtful analysis. In group 3, the students were well able to identify the issues from the amnesty international report and did a fairly good mapping of them to the social sustainability principles. It was still tricky for them to identify structural obstacles (so laws or norms) that were underlying this issue but came up with some good ideas of how organizations could try to counter these issues. Group 4 had a harder time with the amnesty international report but managed to identify the issues quite well in the end and did a good mapping to the SSPs. The found the structural obstacles also trickier but managed some good analysis. They misunderstood how to think about an organization's connection to these structural obstacles.

Group 3 reflected that they found the sorting of the issues challenging, but that once they were sorted the structural obstacle identification was easy. They thought the instructions made a lot of difference in terms of structure but also thought the amnesty website helped a lot to know more about another country. Group 4 reflected that it was tricky to study conditions in a new country and that the exercise widened their perspective; they also acknowledged that a lot of knowledge is required to identify structural obstacles in a country that one potentially knows very little about.

\section{Discussion}

Our overall reflection is that the engineering students continue to struggle with social sustainability; many did not (some even after the exercise) see the connection between social sustainability and products nor the relevance of social sustainability to their field of study. Many found it hard to understand the task. In addition, in the structured process many also found it difficult to read the amnesty international report and seemed unfamiliar with thinking critically about the themes presented. To be fair, none of the students were working in their native language. However, they had all been instructed on the material in English before and the master's students are taking an entire program in English.

Building on that many students acknowledged that the approach with limited instructions built extensively on prior knowledge of social issues. Some clearly did not come with a lot of that and therefore struggled. Many of those felt the second process was easier because "it gave you the information" or "the right answer". However, some in this group also saw no difference in the results that the two processes produced. Interestingly the groups were also not always able to build on their prior knowledge or learning. For example, the bachelor's class had already worked extensively on a life-cycle analysis from the perspective of ecological impacts, but only a few groups also applied this to the social analysis initially. This implies that they either did not perceive this approach as relevant for a social analysis, so made an active choice about it, or had not yet internalized this as the most appropriate approach for a structured sustainability analysis of any kind.

Given the short time frame, bachelor's students on the second round struggled to make it all the way to step on identifying structural obstacles. They spent more time on discussing the issues and mapping them to social sustainability principles and the results also show an improvement in this area. This, to us, is another indicator that they are generally unfamiliar with these kinds of issues and are despite 
prior lectures not as well versed in the social sustainability principles. As the instructors, we would consider this step of identifying (in a given text) and mapping easier than identifying structural obstacles. However, the results from the workshop with the master's students show that the students who do have more time are aided by the process and come up with fairly good assessments also on the structural obstacles.

Interestingly the students who created better results also appreciated the guidance more. They voiced that social sustainability issues were complex challenges that were aided by a structured process. Finally, some students who did extremely well voiced that they saw no differences in the two process because they would have done the same process as in the structured approach upfront. This indicates that students who are well versed in the issues and the complexity of the field do not require the same level of guidance, but by themselves take a structure and systematic approach. However, learning support must not only target high performing students but help students with little knowledge reach similar results.

These struggles suggest to us that supporting engineering students in working with social sustainability analysis needs to start at very basic level with familiarizing them with social issues (around the world) in general and helping them to understand why these issues are relevant also for engineers. This means building basic knowledge and motivating the students and requires different approaches than only teaching them how to do a social sustainability analysis. The structured approach we provided did some of that, but not enough. It is not clear why, but it seems that students have an easier time connecting ecological sustainability issues to their work, perhaps because more media attention is paid to it or because more processes exist to help them do so.

For future use we would recommend giving more time to students to grapple with social sustainability issues both in the curriculum in general and also this particular support process. For the latter we would spend more time in helping the students to make connections between their field of study and social sustainability as well as the different steps of the exercise. For example, we would help them to understand why focusing on countries is relevant by clarifying the mutual interdependencies between product lifecycle stages, industry sectors and different national contexts regarding practices and regulatory frameworks that ultimately determine structural obstacles.

The study does of course have its limitations. The sample size was fairly small and the timeframe for the students to do the exercise short, especially in the bachelor level class. Further, teachers asking students about their reflections can be challenging as there is no guarantee that what they write is actually how they feel as opposed to what they think the teacher wants to hear. And finally, there is a certain subjective circularity to the research design: the teachers designed a certain process to support students and they also evaluated whether the results the students produced through this process had a certain quality. Ideally, the assessment would have been done by a third-party with a different set of evaluation criteria, but such are the limitations of designing a study within the constraints of an academic course.

\section{Conclusion}

Despite the limitations outlined above, we can conclude that the engineering students in this study remain challenged in working rigorously and systematically with social sustainability issues. We suspect that this might also be the case at many other institutions besides BTH and KTH (Edvardsson Björnberg et al., 2015). We argue that scaffolded support not only helps them to create better assessment but to learn in the process. However, this scaffolding takes time and requires that engineering courses set aside time to address these issues and give it weight in their curriculum. Our experience is that that is tricky and not seen as a priority in engineering education in general (see Lönngren, 2019 for similar results on integrating ethics). However, given the state of the world it is of utmost importance that we support the development of socially aware and therefore qualified engineers who do not perpetuate the problems the world is currently facing but help address them. 


\section{References}

Barry, J. (2012), The Politics of Actually Existing Unsustainability: Human Flourishing in a Climate-Changed, Carbon-Constrained World, Oxford University Press, Oxford. https://doi.org/10.1093/acprof:oso/ 9780199695393.001.0001

Benoît, C. et al. (2010), "The guidelines for social life cycle assessment of products: just in time!", The International Journal of Life Cycle Assessment, Vol. 15 No. 2, pp. 156-163. https://doi.org/10.1007/s11367009-0147-8

Blewitt, J. (2010), "Higher education for a sustainable world", Education \& Training, Vol. 52 No. 6/7, pp. 477488. https://doi.org/10.1108/00400911011068432

Crawley, E.F. et al. (2011), "The CDIO syllabus v2. 0. An updated statement of goals for engineering education", In: Proceedings of 7th international CDIO conference, Copenhagen, Denmark.

Dreyer, L., Hauschild, M. and Schierbeck, J. (2005), "A Framework for Social LifeCycle Impact Assessment”, The International Journal of Life Cycle Assessment, Vol. 11 No. 2, pp. 88-97. https://doi.org/10.1065/ lca2005.08.223

Edvardsson Björnberg, K., Skogh, I.-B. and Strömberg, E. (2015), "Integrating social sustainability in engineering education at the KTH Royal Institute of Technology", International Journal of Sustainability in Higher Education, Vol. 16 No. 5, pp. 639-649. http://dx.doi.org/10.1108/ijshe-01-2014-0010

El-Zein, A. et al. (2008), "Sustainability and ethics as decision-making paradigms in engineering curricula", International Journal of Sustainability in Higher Education, Vol. 9 No. 2, pp. 170-182. https://doi.org/ $10.1108 / 14676370810856314$

Fitzpatrick, J.J. (2016), "Does engineering education need to engage more with the economic and social aspects of sustainability?”, European Journal of Engineering Education, Vol. 42 No. 6, pp. 916-926. http://doi.org/ 10.1080/03043797.2016.1233167

Forum for the Future (2000), The engineer of the 21st century inquiry - engineers for sustainability, Available at http://www.forumforthefuture.org.uk/uploadstore/Engineers_for_Sustainability.pdf, UK, London.

Jones, S.A. and Michelfelder, D.P. (2015), From Caring about Sustainability to Developing Care-ful Engineers, Engineering Faculty Publications and Presentations, Available at: http://pilotscholars.up.edu/egr_facpubs/37.

Lönngren, J. (2019), "Exploring the discursive construction of ethics in an introductory engineering course", proceedings of the 8th research in engineering education symposium, rees 2019 - making connections, pp. 262.

Missimer, M., Robèrt, K.-H. and Broman, G. (2017a), "A strategic approach to social sustainability - Part 1: exploring the social system", Journal of Cleaner Production, No. 140, pp. 32-41. http://dx.doi.org/10.1016/ j.jclepro.2016.03.170

Missimer, M., Robèrt, K.-H. and Broman, G. (2017b), "A strategic approach to social sustainability - Part 2: a principle-based definition”, Journal of Cleaner Production, No. 140, pp. 42-52. http://dx.doi.org/10.1016/ j.jclepro.2016.04.059

SFS (1993), Högskoleförordningen (The Higher Education Ordinance), Available at: https://www.uhr.se/en/ start/laws-and-regulations/Laws-and-regulations/The-Higher-Education-Ordinance/ (Accessed Nov 13th, 2019).

Steffen, W. et al. (2011), "The Anthropocene: From Global Change to Planetary Stewardship", AMBIO, Vol. 40 No. 7, pp. 739-761. http://dx.doi.org/10.1007/s13280-011-0185-x

Sustainable Development Solutions Network (2017), SDG Index and Dashboards Report 2017, Compact edition, Bertelsmann Stiftung \& Pica Publishing.

UNESCO (2005), United Nations Decade of Education for Sustainable Development (2005-2014), United Nations Educational, Cultural and Scientific Organisation, Paris.

WWF (2010), Living Planet Report. Biodiversity, biocapacity and development, Gland, World Wildlife Fund, Switzerland. 